\title{
Discussion on the Method of Applying Outward Bound to College Physical Education
}

\author{
Jiabin Zhang \\ Taishan University Tai'an Shandong 271000, China.
}

Keywords: physical education; outward bound; methods; application.

\begin{abstract}
The reform of education system and social development have paid more attention to the comprehensive training with students, and physical education, as a significant factor in the teaching to promote the overall development of students, has also gradually accepted the wide attention from all walks of life. Sports can not only help students train their bodies but also make them understand the sports spirit in the sports learning, learn the correct methods of sports training, train the teamwork ability and improve the personal quality. But in the physical education, some teachers still adopt traditional teaching methods and use few methods of outward bound, which is not helpful to improve the quality of class teaching. This paper made the analysis of the methods of applying outward bound to physical education based on the teaching practice, aiming at providing the reference for physical teaching and promoting the development of sporting teaching.
\end{abstract}

\section{Introduction}

College education has attached more importance to physical teaching along with the development of society and reform of education system. Even some colleges launch the specific courses for those students good at sports to make them trained professionally. However, there still exist some problems in the current physical teaching, which can't improve the physical teaching quality. Outward bound, as one of the scientific and high-effective sports training method, mainly specifically train students according to their characteristics and train their will, bodies, mental quality and positive life attitude by creating representative scenario and exercise method. Therefore, the application of outward bound in the physical teaching has gained wide attention and the application methods also are focused on.

\section{Meaning and Characteristics of Outward Bound}

Originated from Europe, outward bound is a project that sets the specialty and challenge via specific scenario, letting the trainee personally experience the sports activity. It aims at training students' mental quality, will, bodies and teamwork awareness to help students form positive life attitude. Outward bound, as a scientific and effective sports training method, has the following characteristics:

\subsection{Comprehensive activity}

It means that the field and time of outward bound are not be limited, and it can be at any field and any time. In addition, the activity has multiple modes, for example, the outdoor activity, indoor activity and specific activity field. What's more, outward bound can set different activity contents and methods according to different group characteristics, flexible and full of comprehensiveness.

\subsection{Challenging}

The purposes of outward bound are to transcend oneself, melt the team and improve the living and development ability of individual or group, which decides its challenge. There are varieties of activity methods, different from general physical training. Most of outward bound activities are more challenging, and this challenge is not only the individual limited challenge for the participator but for the team, to make the participator challenge himself and give full play to his potential. 


\subsection{Self-Education}

Self-education means that activity participators can find his own shortcomings in the process of outward bound and improve their own ability and quality through the training. Outward bound enables the participator to challenge through setting different activity contents based on the specific scenario and can help them strengthen their own ability and teamwork awareness to realize self-education.

\section{Necessity of Applying Outward Bound to the Physical Teaching}

\subsection{Demand of Social Development}

Social development has made an increasing demand and requirements for talents, which refers to the talents with strong professional ability, high political and ideological level as well as good physical quality. In addition, the country also promotes that college teaching should improve the comprehensive development of students and pay attention to strengthening their physical quality and encourage them to participate in more sports training. College sports teaching, as the significant course of improving students' physical qualities, can make students participate in the physical training in the sports class, learn correct physical training methods and improve their physical qualities. Therefore, the application of outward bound in the physical teaching, as the demand of social development, should follow the tide of era development.

\subsection{Necessity of Improving Students' Physical Qualities}

Students not only have lots of courses and subjects to study and heavy study tasks in the school but little time to participate in the physical training. Although physical class is a significant course to make students have sports training in the school, teachers just make students have warming-up and then dissolve them. Students are seldom organized to take part in the physical training so that their physical qualities are not high in the whole. The application of outward bound in the physical teaching can make students fully participate in the sports class teaching and obtaining the training in the activity is the necessary condition to improve students' physical qualities.

\section{Application Methods of Outward Bound in the Physical Teaching}

In the current physical teaching, outward bound has not been widely applied to the physical teaching due to the indifference of teachers and parents, and the incorrect training methods of teachers also has made the effect of outward bound not obvious. As an effective physical teaching method, outward bound mainly includes three models: classroom experience, outdoors and professional field. However, considering the condition limit and students' security, college physical teaching mostly makes the outward bound in the school. The following methods of applying outward bound to the physical teaching can be adopted.

\subsection{Method of Scenario Simulation}

Scenario simulation means that teachers let students make the scenario simulation in the teaching process by setting activity projects based on the specific scenario contents. In the colleges, the condition limit and students' security being considered, students have few chances to make outward bound. Therefore, when applying outward bound to the physical teaching, teachers can adopt the method of scenario simulation. They can set the scenario via the sports props, assuming that students are making outward bound in the specific outdoors scenario to improve students' zeal and initiative with sports training and make them participate in the activity.

\subsection{Method of Experiential Learning}

Experiential learning, the most fundamental learning mode of students, means that students can learn some skills and form certain habits that will exert some effects on their own characteristics and habits even the value and outlook on life through the repeated observation and practice coupled with their own experience that help them realize the essence of things. So applying the outward bound to the physical teaching can adopt the method of experiential learning, which means that students should participate in the challenge personally and make their own breakthrough. Such method is able to help 
students not only learn the skills of sports training and basic outdoor living skills in the outward bound but train their firm will, form the good habits and improve the awareness of teamwork. This method is widely used in the outward bound, making students be in the outdoor activity and truly experience so as to give full play to effect of outward bound. For example, when making the sports teaching in the good-condition colleges, teachers may organize student to have the climbing in the specific climbing training base and let students finish the climbing by themselves to personally experience the skills needed to be noticed in the process and train the will.

\subsection{Method of Cooperative Learning}

Cooperative learning is one of the effective methods to train the teamwork ability of students, and students can achieve their purposes through the cooperative method in the practice. The application of outward bound in the physical teaching can adopt the method of cooperative learning, which can let students communicate with each other through the activity setting by the teacher and find proper methods to finish the activity by the means of cooperation. By this way, students can learn the significance of teamwork, improve the teamwork awareness and train their own ability. For instance: in the game The Blind Phalanx in the physical class teaching, the teacher can divide students into several groups and let all the members of each group cover their eyes to pull a rope into a biggest square within the schedule time. In addition, all the members are supposed to averagely divided on the four sides, and the group with the least time to finish is the winner. During this game, members of each group should communicate with each other at first to confirm the game plan and then choose an instructor who should be equipped with pretty ability of language expression and organization so as to rationally allocate the members in the game. And then the task should be quickly finished with the teamwork of all the members. This game belongs to a teamwork game, which needs students cooperate and trust each other, and it can strengthen the teamwork ability of students. As for the instructor of the game, their leadership can be trained.

\subsection{Method of Inquiry Learning}

Inquiry learning means that students can obtain the knowledge, improve skills and broaden the thought based on their own conjecture or assumption and scientific research under the premise of students' initiative participation. It is an effective learning method. As a significant course to improve the physical quality and teamwork awareness of students in the teaching, physical education exerts an important effect on the individual development of students. Teachers can adopt the method of inquiry learning to train students to learn the methods to autonomously study and solve problems in the outward bound, which can not only train students' bodies and teamwork awareness but give full play to their own initiative and broaden the thought in the process of outward bound.

\subsection{Method of Self-Assessment}

In the process of teamwork, students may think that someone else in the team has made the mistake at first if the task is not finished, not thinking themselves, which will cause the mutual criticism and suspicion. Method of self-assessment means that students should have correct evaluation with themselves in the practice, know their shortcomings and mistakes in the activity, learn to find the reasons of themselves and actively correct them so that they can make the contribution to the team rather than dragging down the whole team. Teachers can help students correctly assess themselves through the game and find their disadvantages and actively correct them to improve the cooperation ability of team. In addition, the introspective habit of students can be trained. For example, when teachers are making the game of "Qimei Stick", the specific game method is that all the students are supposed to be divided into two groups, standing face to face. And they need to put a stick with the length of three meters on the ground with the same one finger. The game will over if the hand leaves the stick. It is a game that fully tests the teamwork ability of students. Because the target cannot be finished if there is failure of any person, every participator is supposed to carefully treat the game and find the reasons of themselves when the game fails. What's more, students should obey the instruction and coordinate with other members to finish the game together. 


\section{Summary}

In summary, with the reform of social development and education system, outward bound, as one kind of effective training project, has been widely applied to the daily physical exercise of staffs in some enterprises, and it also has gradually been popular with students and applied to the college physical teaching. As the significant course in the spare time of students, sports course has gained great popularity among students and so has the application of outward bound in the physical teaching. However, teachers usually cannot teach according to the study characteristics of students in the physical teaching, which makes the outward bound lose its original meaning. Therefore, when outward bound is applied to the physical teaching, teachers should teach students based on the teaching condition and students' characteristics and find proper methods, for example, scenario simulation, cooperative learning, inquiry learning and self-assessment. These methods can make students train their bodies and improve the ability of teamwork in the physical outward bound so as to give full play to the effect of outward bound in the physical teaching.

\section{References}

[1]. Hongjun Zhai. Analysis on the application of outward bound in the college physical teaching[J]. Education Review (the Edition of Last Ten Day), 2014(4):55-57.

[2]. Yang Yang. Thought on the Application of Outward Bound in the College Physical Teaching[J]. Education Innovation Herald-Electronic Edition (the Edition of Last Ten Day), 2015(1):95.

[3]. Mei Yang. Application of Contents and Methods of Outward Bound in the Vocational Physical Teaching[J]. Technology Vision, 2014(27): 227,332. 